\title{
Simple cooking methods flush arsenic out of rice
}

\section{Preparing rice in a coffee machine can halve levels of the naturally occurring substance.}

\section{Emily Sohn}

22 July 2015

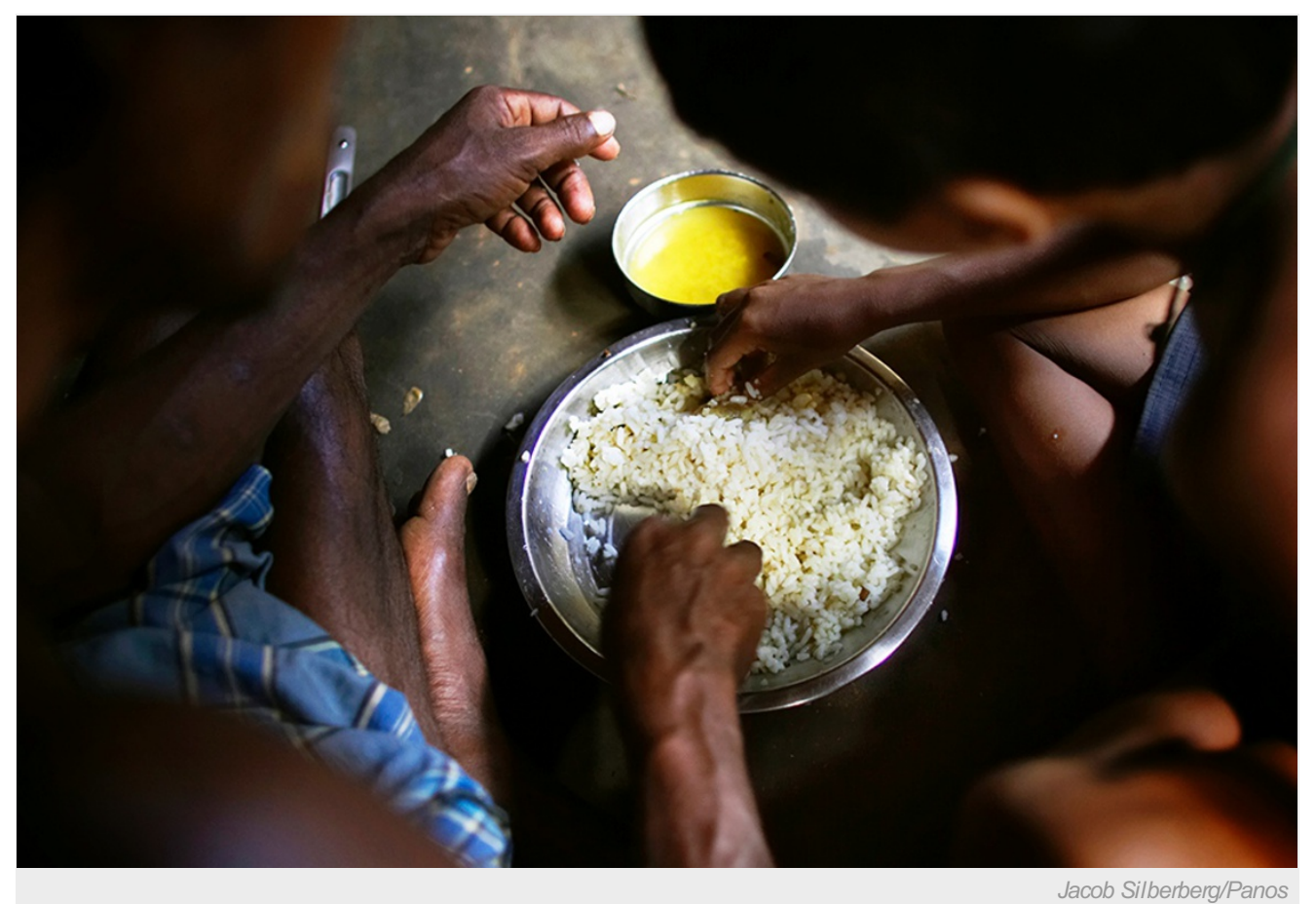

Rice is the staple food of many people, but it can contain dangerous levels of arsenic.

Cooking rice by repeatedly flushing it through with fresh hot water can remove much of the grain's stored arsenic, researchers have found - a tip that could lessen levels of the toxic substance in one of the world's most popular foods.

Billions of people eat rice daily, but it contributes more arsenic to the human diet than any other food. Conventionally grown in flooded paddies, rice takes up more arsenic (which occurs naturally in water and soil as part of an inorganic compound) than do other grains. High levels of arsenic in food have been linked to different types of cancer, and other health problems.

Andrew Meharg, a plant and soil scientist at Queen's University Belfast, UK, wondered whether cooking the grain in a different way might help to lessen the health risk. The standard method for making rice — boiling it in a pot until it soaks up all the liquid — binds into place any arsenic contained in the rice and the cooking water.

\section{Percolation is key}

On the basis of earlier work, Meharg and his colleagues knew that arsenic levels drop when rice is thoroughly rinsed and then cooked in an excessive amount of water. The method helps even when the cooking water contains arsenic.

Meharg and colleagues found that using this method with increasing proportions of water removed progressively more arsenic — up to a $57 \%$ reduction with a ratio of 12 parts water to one part rice. That result confirmed that the arsenic is 'mobile' in liquid water, and thus can be removed.

The team then cooked rice in an apparatus that continually condenses steam to produce a fresh supply of distilled hot water, and in an ordinary coffee percolator with a filter, which allows cooking water to drip out of the rice. Testing the rice before and after cooking showed that coffee-pot percolation removed about half the arsenic, and that the lab apparatus removed around 60-70\%. In some cases, the technique removed as much as $85 \%$ of the substance, depending on the type of rice used. The findings are reported in PLOS ONE ${ }^{1}$. 


\section{Short-term fix}

Meharg does not expect people to start cooking rice in their coffee machines. "We just took something that's in everybody's kitchen and applied it to show a principle," he says. He sees the research as a proof of concept that could feed the development of simple, inexpensive rice cookers that lower arsenic concentrations.

The risk of arsenic poisoning is greatest for consumers who eat rice several times a day. In Bangladesh, where rice is a staple and the water is also naturally high in arsenic, people are particularly vulnerable. Parboiling facilities in the country process rice by precooking, drying and husking the grain. These processes offer the opportunity to intervene on a commercial scale with cookers that would reduce arsenic levels — something that Meharg plans to do.

The same technique could also help companies elsewhere to lower arsenic levels in baby cereals and other products that use precooked rice. Rice-based baby foods often contain high levels of arsenic ${ }^{2}$, a double-whammy for small children, who consume proportionately more of the substance for their body size.

In the long term, the best strategies for removing arsenic from rice will come from ongoing efforts to breed low-arsenic strains and alter growing techniques, says Margaret Karagas, an epidemiologist at Dartmouth College in Hanover, New Hampshire. But, she says, "This paper is really interesting because it is offering a short-term solution to the problem. It's giving people an opportunity to reduce the arsenic burden of their rice."

Nature I doi:10.1038/nature.2015.18034

\section{References}

1. Carey, M. et al. PLoS ONE http://dx.plos.org/10.1371/journal.pone.0131608 (2015).

2. Signes-Pastor, A. J., Carey, M. \& Meharg, A. A. Food Chem. http://dx.doi.org/10.1016/j.foodchem.2014.11.078 (in the press). 